\title{
Efficient conversion of acetate into lipids by the oleaginous yeast Cryptococcus curvatus
}

\author{
Zhiwei Gong ${ }^{1,2^{*}}$, Hongwei Shen ${ }^{2}$, Wengting Zhou' ${ }^{1}$ Yandan Wang ${ }^{2}$, Xiaobing Yang ${ }^{2}$ and Zongbao K. Zhao ${ }^{2^{*}}$
}

\begin{abstract}
Background: Acetic acid is routinely generated during lignocelluloses degradation, syngas fermentation, dark hydrogen fermentation and other anaerobic bioprocesses. Acetate stream is commonly regarded as a by-product and detrimental to microbial cell growth. Conversion of acetate into lipids by oleaginous yeasts may be a good choice to turn the by-product into treasure.

Results: Ten well-known oleaginous yeasts were evaluated for lipid production on acetate under flask culture conditions. It was found that all of those yeasts could use acetate for microbial lipid production. In particular, Cryptococcus curvatus accumulated lipids up to $73.4 \%$ of its dry cell mass weight. When the culture was held in a 3-L stirred-tank bioreactor, cell mass, lipid content, lipid yield and acetate consumption rate were $8.1 \mathrm{~g} / \mathrm{L}, 49.9 \%, 0.15 \mathrm{~g} / \mathrm{g}$ and $0.64 \mathrm{~g} / \mathrm{L} / \mathrm{h}$, respectively. The fatty acid compositional profiles of the acetate-derived lipids were similar to those of vegetable oil, suggesting their potential for biodiesel production. Continuous cultivation of $C$. curvatus was conducted under nitrogen-rich condition at a dilution rate of $0.04 \mathrm{~h}^{-1}$, the maximal lipid content and lipid yield were $56.7 \%$ and $0.18 \mathrm{~g} / \mathrm{g}$, respectively. The specific lipid formation rate, lipid content and lipid yield were all higher under nitrogen-rich conditions than those obtained under nitrogen-limited conditions at the same dilution rates. Effective lipid production by C. curvatus was observed on corn stover hydrolysates containing $15.9 \mathrm{~g} / \mathrm{L}$ acetate.

Conclusions: Acetate is an effective carbon source for microbial lipid production by oleaginous yeasts. Continuous cultivation of C. curvatus on acetate was promising for lipid production under both nitrogen-rich and nitrogen-limited conditions. These results provide valuable information for developing and designing more efficient acetate-into-lipids bioprocess.
\end{abstract}

Keywords: Oleaginous yeast, Cryptococcus curvatus, Acetic acid, Continuous culture, Microbial lipids, Biodiesel, Biomass hydrolysates

\section{Background}

Microbial lipids generated from low-cost substrates are potential alternative feedstock for biodiesel and oleochemical industries $[1,2]$. Some oleaginous yeasts can accumulate lipids up to $70 \%$ of their dry cell weight [3]. When sugars and related materials are used as substrates,

\footnotetext{
*Correspondence: gongzhiwei@wust.edu.cn; zhaozb@dicp.ac.cn ${ }^{1}$ College of Chemical Engineering and Technology, Wuhan University of Science and Technology, 947 Heping Road, Wuhan 430081, People's Republic of China

${ }^{2}$ Dalian National Laboratory for Clean Energy and Dalian Institute of Chemical Physics, CAS, 457 Zhongshan Road, Dalian 116023, People's Republic of China
}

lipid biosynthesis is often triggered by limitation of macronutrients, such as nitrogen or phosphate $[4,5]$.

Acetate is routinely present in aqueous stream of various biological processes but commonly recognized as a by-product. For example, because hemicelluloses are generally acetylated [6], biomass hydrolysates contain acetate [7]. In addition, acetate is co-produced during syngas fermentation, dark hydrogen fermentation and other anaerobic bioprocesses [8-11]. Recently, Acetobacterium woodii has been reported to produce $51 \mathrm{~g} / \mathrm{L}$ of acetate from $\mathrm{CO}_{2} / \mathrm{H}_{2}$ [12]. Acetate has been known as an inhibitor for cell growth of some oleaginous microorganisms $[7,13,14]$. 
It is worth mentioning that acetate has been proven toxic to cell growth but beneficial to lipid accumulation by the yeast Rhodosporidium toruloides Y4 [15]. It is conceivable that acetate can be assimilated and converted into acetyl-CoA, the precursor to lipid biosynthesis [3, 16]. The metabolic scheme and associated stoichiometric equations have already been established previously [17]. More recently, acetate has been explored as substrate for the cultivation of oleaginous species [10, 11, 18-21]. Volatile fatty acids (mixtures of acetate, propionate and butyrate) at a low concentration of $2 \mathrm{~g} / \mathrm{L}$ were sufficient to support Cryptococcus albidus cells for lipid production and lipid yield reached $0.167 \mathrm{~g} / \mathrm{g}$ [18]. Because Cryptococcus curvatus and Yarrowia lipolytica exhibited poor cell growth on acetate, a two-stage culture process, cell proliferation on glucose and lipid biosynthesis on acetate, was developed. Lipid content and lipid yield for C. curvatus cells were $50 \%$ and $0.15 \mathrm{~g} / \mathrm{g}$, and for Y. lipolytica, $40.7 \%$ and $0.13 \mathrm{~g} / \mathrm{g}$, respectively $[19,20]$. C. curvatus has been confirmed to grow better under neutral condition than acidic condition when acetate is the sole carbon source. A pH-stat culture fed with pure acetate was then established. Cell mass and lipid content reached $168 \mathrm{~g} / \mathrm{L}$ and $75.0 \%$, respectively [10]. However, fed-batch culture on acetate might not be viable because acetate is usually present in aqueous stream of various biological processes at relatively low concentrations.

Continuous culture has been regarded as a promising strategy for lipid production [22-25]. When a stream containing acetate at low concentration is considered as feedstock, continuous culture may be more appropriate for lipid production. Previously, continuous cultivation of $C$. curvatus cells on hydrogen production effluent containing acetate has been investigated, and cellular lipid content was only $13.5 \%$ [10]. To further explore the potential of lipid production on acetate, here we screened ten well-known oleaginous yeasts under flask culture conditions, and identified C. curvatus as a superior strain for such purpose. Continuous cultures under nitrogenrich or nitrogen-limited conditions were evaluated, and the results provided useful information for developing and designing more efficient acetate-into-lipids bioprocess.

\section{Results and discussion}

\section{Batch culture for lipid production on acetate}

Short chain organic acids, especially acetate, have been reported suitable for lipid production by several oleaginous yeasts $[10,11,18,20,21]$. However, the capacities of lipid production on acetate have not been systematically compared and evaluated. In this study, ten well-known oleaginous yeasts were evaluated for lipid production using acetate as sole carbon source, and the results are shown in Table 1. It was clear that all of these oleaginous yeasts over-produced lipids. Among them, Trichosporon cutaneum AS 2.571, Trichosporon fermentans CICC 1368, C. curvatus ATCC 20509 and R. toruloides $\mathrm{Y} 4$ achieved lipid contents more than $50 \%$ of their dry cell weight when the cultures were terminated after $72 \mathrm{~h}$. The highest cell mass and lipid titre were 7.5 and $4.4 \mathrm{~g} / \mathrm{L}$, respectively, by T. cutaneum, and the highest lipid content reached $73.4 \%$ by C. curvatus.

Optimal culture $\mathrm{pH}$ range was between 5.0 and 6.0 during lipid production from sugars by most oleaginous yeasts [26, 27]. However, all these yeasts grew unsuccessfully in acetate assimilation medium when the initial $\mathrm{pH}$ was set at 5.5 (data not shown). Because acetate has a $\mathrm{p} K \mathrm{a}$ of 4.75 , at acidic $\mathrm{pH}$, acetate appears largely in undissociated form, which imposes inhibitory effects on cell proliferation; however, acetic acid in its dissociated form is much less toxic [6]. When the culture $\mathrm{pH}$ was at 5.5 , about $15 \%$ acetic acid was in the undissociated form, which exerted inhibitory effect on cell growth. When the cultures were at $\mathrm{pH}$ 7.0, $99 \%$ acetic acid was dissociated

Table 1 Results of lipid production on acetate by oleaginous yeasts

\begin{tabular}{lllll}
\hline Strain & $\mathbf{\Delta} \mathbf{p H}^{\mathbf{a}}$ & Cell mass $(\mathbf{g} / \mathbf{L})$ & Lipid (g/L) & Lipid content (\%) \\
\hline L. starkeyi AS 2.1560 & $2.07 \pm 0.02$ & $3.2 \pm 0.2$ & $0.6 \pm 0.1$ & $17.1 \pm 1.4$ \\
Y. lipolytica AS 2.1398 & $2.10 \pm 0.01$ & $4.1 \pm 0.5$ & $0.5 \pm 0.0$ & $12.2 \pm 0.4$ \\
T. cutaneum AS 2.571 & $2.40 \pm 0.02$ & $7.5 \pm 0.1$ & $4.4 \pm 0.0$ & $58.5 \pm 0.5$ \\
T. fermentans CICC 1368 & $2.35 \pm 0.02$ & $6.8 \pm 0.5$ & $3.8 \pm 0.3$ & $55.4 \pm 0.8$ \\
R. glutinis AS 2.107 & $2.26 \pm 0.02$ & $2.5 \pm 0.1$ & $0.7 \pm 0.1$ & $27.0 \pm 2.1$ \\
R. mucilaginosa AS 2.1515 & $2.03 \pm 0.04$ & $2.6 \pm 0.2$ & $0.6 \pm 0.1$ & $21.8 \pm 0.6$ \\
R. minuta AS 2.277 & $2.02 \pm 0.01$ & $1.8 \pm 0.1$ & $0.5 \pm 0.0$ & $30.2 \pm 0.3$ \\
C. curvatus ATCC 20509 & $2.38 \pm 0.01$ & $5.7 \pm 0.1$ & $4.2 \pm 0.1$ & $73.4 \pm 0.6$ \\
R. toruloides ATCC 10788 & $2.26 \pm 0.03$ & $1.2 \pm 0.0$ & $0.4 \pm 0.0$ & $33.0 \pm 3.0$ \\
R. toruloides Y4 & $2.38 \pm 0.02$ & $2.6 \pm 0.3$ & $1.5 \pm 0.2$ & $54.9 \pm 1.3$ \\
\hline
\end{tabular}

a Delta $\mathrm{pH}(\Delta \mathrm{pH})$ was obtained by subtracting the initial $\mathrm{pH}$ value from the final $\mathrm{pH}$ value 
into acetate anion. It was found that culture $\mathrm{pH}$ increased over time to above 9.0 at the end of the culture, indicating the consumption of acetate in the medium. Therefore, a nitrogen-limited batch culture of C. curvatus was performed in a 3-L stirred-tank bioreactor to keep $\mathrm{pH}$ constant. Culture $\mathrm{pH}$, temperature, agitation and aeration rate were set at $7.0,30^{\circ} \mathrm{C}, 500 \mathrm{rpm}$ and $0.8 \mathrm{vvm}$, respectively. Our results indicated that $26.4 \mathrm{~g} / \mathrm{L}$ of acetate was consumed within $41.3 \mathrm{~h}$ (Fig. 1a), corresponding to an acetate consumption rate of $0.64 \mathrm{~g} / \mathrm{L} / \mathrm{h}$. Cell mass, lipid content, lipid yield and lipid productivity were $8.1 \mathrm{~g} / \mathrm{L}$, $49.9 \%, 0.15 \mathrm{~g} / \mathrm{g}$ and $2.32 \mathrm{~g} / \mathrm{L} / \mathrm{d}$, respectively. The lipid content and lipid yield were similar to those obtained by C. curvatus under two-stage fed-batch culture conditions [19]. It was also found that non-lipid cell mass increased continuously (Fig. 1b), which was different from the general trend that oleaginous yeasts favored lipid biosynthesis rather than cell proliferation under nitrogen-limited conditions [4]. In fact, Cryptococcus terricola was the only reported oleaginous yeast that produced lipids in growth phase, albeit on glucose [28].

Microbial lipids produced from acetate by C. curvatus were transmethylated and fatty acid compositional profiles were analyzed by gas chromatography. It was found that the sample consisted mainly of long-chain fatty acids with 16 and 18 carbon atoms, including $0.9 \%$ myristic acid, $32.0 \%$ palmitic acid, $0.4 \%$ palmitoleic acid, $23.6 \%$ stearic acid, $39.5 \%$ oleic acid and $0.2 \%$ linoleic acid. Specifically, palmitic acid, stearic acid and oleic acid together accounted for over $95 \%$ of the total fatty acids, which were similar to the fatty acid compositional profiles of lipids produced from lignocellulosic sugars by the same yeast $[27,29]$. Such compositional profiles were also comparable to those of vegetable oil, suggesting that acetate-derived lipids could be explored for biodiesel production [30].

\section{Continuous cultivation of $C$. curvatus on acetate under nitrogen-rich conditions}

Acetate was evaluated for growing C. curvatus cells in nitrogen-rich medium under continuous culture conditions with dilution rates ranged from 0.04 to $0.14 \mathrm{~h}^{-1}$. Surprisingly, lipid contents were higher than $20 \%$, and lipid content decreased from $56.7 \%$ at a dilution rate of $0.04 \mathrm{~h}^{-1}$ to $25.5 \%$ at a dilution rate of $0.14 \mathrm{~h}^{-1}$ (Table 2). Similarly, lipid yield also dropped from 0.18 to $0.10 \mathrm{~g} / \mathrm{g}$ (Fig. 2). The fact that a lipid yield of $0.18 \mathrm{~g} / \mathrm{g}$ was achieved suggested that the majority of acetate was channeled into lipid biosynthesis. However, the $\mathrm{C} / \mathrm{N}$ ratio of the feeding medium was 1.76 , which was substantially lower than those used for microbial lipid production on sugars and related materials [31,32]. The lipid productivity increased when the dilution rate decreased (Table 2). The highest lipid productivity was $0.73 \mathrm{~g} / \mathrm{L} / \mathrm{d}$ at the dilution
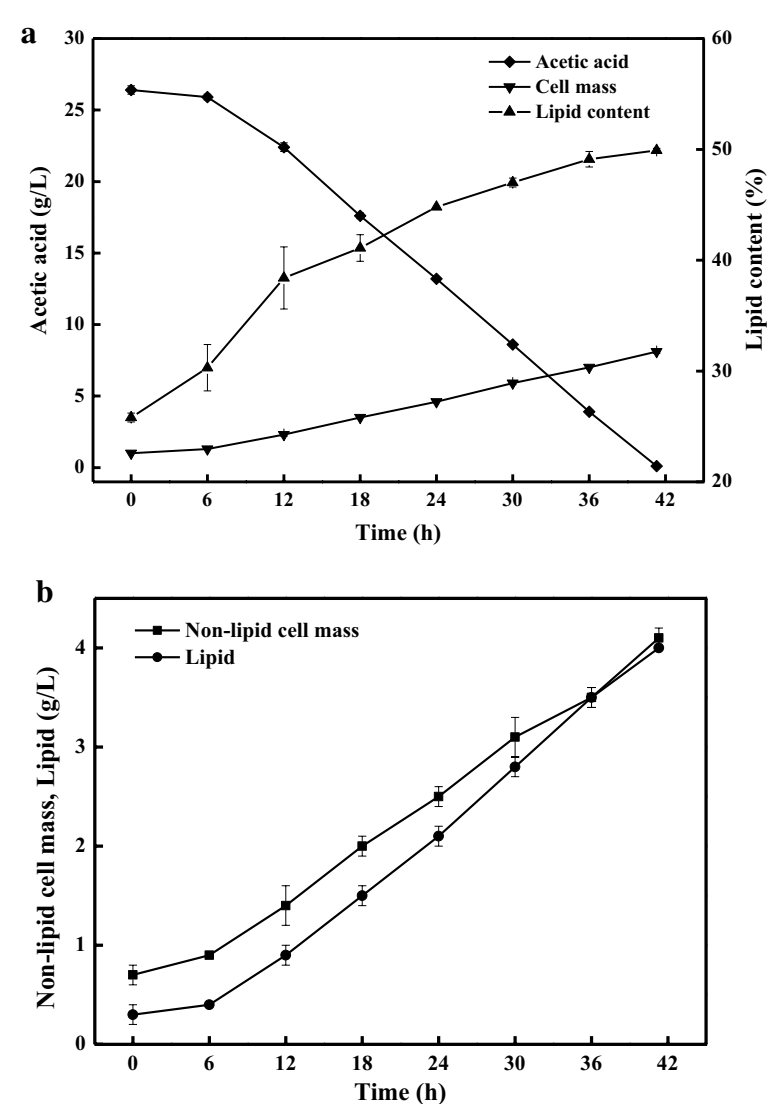

Fig. 1 Results of lipid production by C. curvatus on acetate. a Profiles of acetate consumption, cell growth and lipid accumulation. $\mathbf{b}$ The evolution of lipid and non-lipid cell mass

rate of $0.04 \mathrm{~h}^{-1}$, which was significantly lower than that by batch culture. An early study found that ammonia inhibited cell growth and lipid biosynthesis when C. curvatus was cultivated on acetate at $\mathrm{pH}$ above 7.5 , likely due to the formation of excess intracellular ammonia that inhibited acyl-CoA synthase activity [33]. In the current study at $\mathrm{pH} 7.0$ in the presence of $5.0 \mathrm{~g} / \mathrm{L} \mathrm{NH}_{4} \mathrm{Cl}$, it seemed ammonium had little inhibitory effects on lipid accumulation. It should also be emphasized that the lipid contents of $R$. toruloides were below $10 \%$ at various dilution rates under carbon-limited conditions [25], which was dramatically different from those of $C$. curvatus.

When extra yeast extract $(0.4 \mathrm{~g} / \mathrm{L})$ and peptone $(0.4 \mathrm{~g} / \mathrm{L})$ were added to the nitrogen-rich acetate medium, the $\mathrm{C} / \mathrm{N}$ ratio slightly decreased to 1.67 . However, lipid content dropped dramatically to below $20 \%$ at a dilution rate of $0.08 \mathrm{~h}^{-1}$, this was because organic nitrogen sources facilitated cell growth by supplementing amino acids and related components. On the other hand, inorganic nitrogen sources might be less efficient in terms of supporting cell growth on acetate. 
Table 2 Results of continuous cultivation of C. curvatus at various dilution rates under nitrogen-rich conditions

\begin{tabular}{|c|c|c|c|c|c|c|c|c|}
\hline$D\left(\mathrm{~h}^{-1}\right)$ & $\begin{array}{l}\text { Acetate con- } \\
\text { sumption }(g / L)\end{array}$ & $\begin{array}{l}\text { Residual } \\
\text { acetate (g/L) }\end{array}$ & Cell mass (g/L) & $\begin{array}{l}\text { Non-lipid cell } \\
\text { mass }(g / L)\end{array}$ & Lipid (g/L) & $\begin{array}{l}\text { Lipid content } \\
(\%)\end{array}$ & $\begin{array}{l}\text { lipid yield } \\
\text { (g/g) }\end{array}$ & $\begin{array}{l}\text { Lipid productiv- } \\
\text { ity (g/L/d) }\end{array}$ \\
\hline 0.04 & $4.18 \pm 0.02$ & $0.67 \pm 0.02$ & $1.34 \pm 0.03$ & $0.58 \pm 0.04$ & $0.76 \pm 0.03$ & $56.71 \pm 2.12$ & $0.18 \pm 0.01$ & $0.73 \pm 0.03$ \\
\hline 0.06 & $2.65 \pm 0.07$ & $2.20 \pm 0.07$ & $0.84 \pm 0.02$ & $0.42 \pm 0.01$ & $0.42 \pm 0.02$ & $50.29 \pm 1.43$ & $0.16 \pm 0.01$ & $0.60 \pm 0.02$ \\
\hline 0.08 & $1.88 \pm 0.07$ & $2.97 \pm 0.09$ & $0.66 \pm 0.02$ & $0.39 \pm 0.02$ & $0.27 \pm 0.01$ & $41.17 \pm 1.10$ & $0.15 \pm 0.01$ & $0.52 \pm 0.01$ \\
\hline 0.11 & $0.88 \pm 0.06$ & $3.97 \pm 0.04$ & $0.36 \pm 0.03$ & $0.25 \pm 0.03$ & $0.11 \pm 0.01$ & $31.06 \pm 2.49$ & $0.13 \pm 0.01$ & $0.29 \pm 0.01$ \\
\hline 0.14 & $0.71 \pm 0.07$ & $4.14 \pm 0.07$ & $0.29 \pm 0.02$ & $0.21 \pm 0.02$ & $0.07 \pm 0.01$ & $25.50 \pm 1.02$ & $0.10 \pm 0.01$ & $0.24 \pm 0.01$ \\
\hline
\end{tabular}

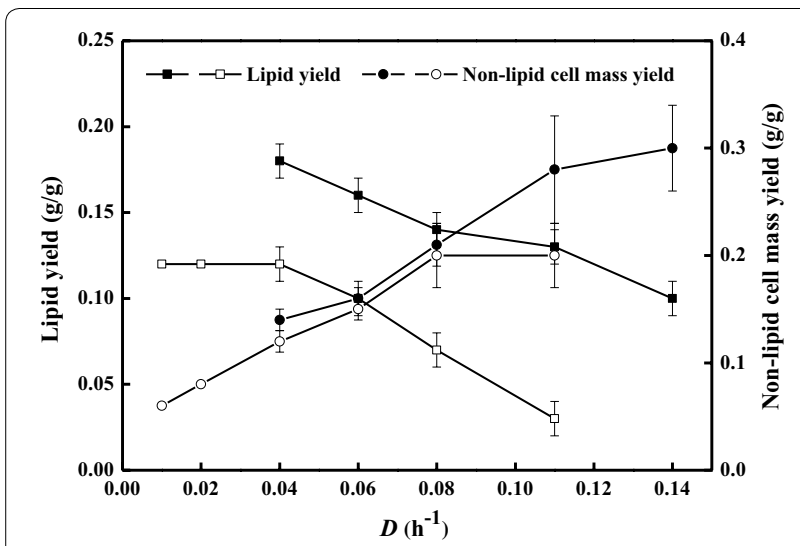

Fig. 2 Steady-state lipid yields and non-lipid cell mass yields of $C$. curvatus at different dilution rates under nitrogen-rich and nitrogenlimited conditions. Error bars mean \pm standard deviation of four samples

The non-lipid cell mass yield increased over the entire dilution rate ranges and reached $0.30 \mathrm{~g} / \mathrm{g}$ at a dilution rate of $0.14 \mathrm{~h}^{-1}$ (Fig. 2), indicating that more acetate was used for cell growth at higher dilution rates. This was likely due that organic nitrogen sources were consumed rapidly for cell growth and thus limited the production of non-lipid cell mass under conditions with lower dilution rates. The maximal cell mass yield of $0.41 \mathrm{~g} / \mathrm{g}$ was obtained at a dilution rate of $0.11 \mathrm{~h}^{-1}$, which was comparable to that of $R$. toruloides under carbon-limited condition using glucose as sole carbon source [25].

The relationship between specific lipid formation rate and dilution rate is shown in Fig. 3. The specific lipid formation rate increased along with the dilution rate from 0.04 to $0.06 \mathrm{~h}^{-1}$, but then dropped when dilution rate increased further. The maximal specific lipid formation rate of $0.061 \mathrm{~g} / \mathrm{g}$ non-lipid cell mass $/ \mathrm{h}$ was observed at the dilution rate $0.06 \mathrm{~h}^{-1}$, which was even higher than that obtained by $R$. toruloides on glucose under the nitrogen-limited condition [25]. As lipid accumulation on sugars and related substrates by oleaginous yeasts is normally triggered by nitrogen

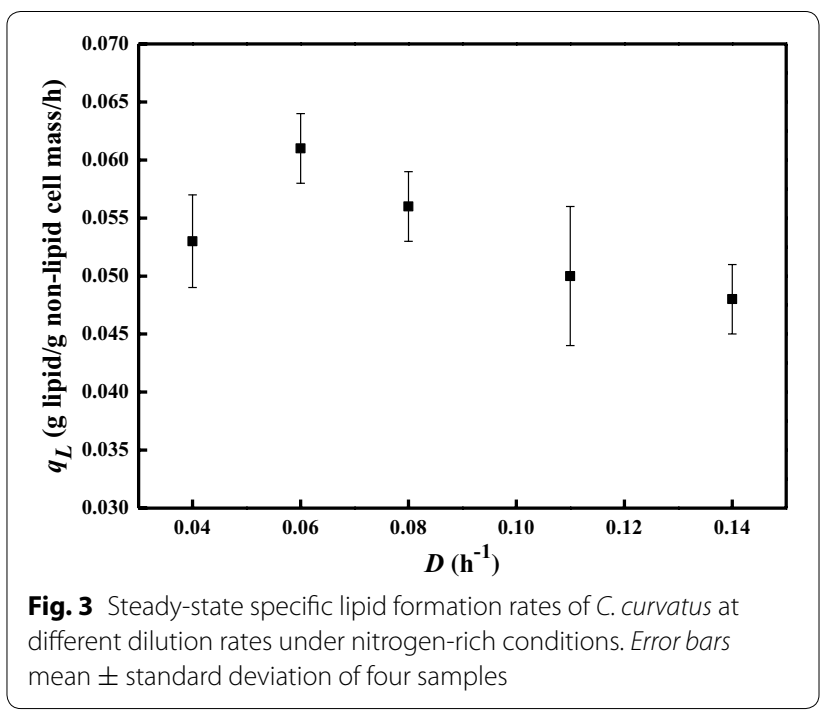

starvation, it is important to remove excess nitrogen from nitrogen-rich substrates [4]. Interestingly, our results demonstrated that lipid production on acetate by $C$. curvatus could be operated under nitrogen-rich conditions, providing new opportunity to use acetatecontaining wastes rich in ammonia nitrogen for microbial lipid production [10].

\section{Continuous cultivation of $C$. curvatus under nitrogen-limited conditions}

Similarly, C. curvatus cells were also cultivated on acetate continuously under nutrient-limited conditions in a three-L stirred-tank bioreactor at dilution rates ranged from 0.01 to $0.11 \mathrm{~h}^{-1}$, and the results are shown in Table 3. Clearly, lipid content increased as the dilution rate decreased. The minimal lipid content was only $14.8 \%$ at a dilution rate of $0.11 \mathrm{~h}^{-1}$, while the maximal lipid content of $66.4 \%$ was obtained at a dilution rate of $0.01 \mathrm{~h}^{-1}$. The results indicated that C. curvatus favored lipid biosynthesis at lower dilution rates. Interestingly, lipid content and lipid yield under nitrogen-limited conditions were always lower than those under nitrogenrich conditions at the same dilution rate (Table 3 vs 
Table 3 Results of continuous cultivation of C. curvatus at various dilution rates under nitrogen-limited conditions

\begin{tabular}{|c|c|c|c|c|c|c|c|c|}
\hline$\overline{D\left(\mathrm{~h}^{-1}\right)}$ & $\begin{array}{l}\text { Acetate con- } \\
\text { sumption (g/L) }\end{array}$ & $\begin{array}{l}\text { Residual } \\
\text { acetate (g/L) }\end{array}$ & Cell mass (g/L) & $\begin{array}{l}\text { Non-lipid cell } \\
\text { mass (g/L) }\end{array}$ & Lipid (g/L) & $\begin{array}{l}\text { Lipid content } \\
(\%)\end{array}$ & $\begin{array}{l}\text { Lipid yield } \\
\text { (g/g) }\end{array}$ & $\begin{array}{l}\text { Lipid productiv- } \\
\text { ity (g/L/d) }\end{array}$ \\
\hline 0.01 & $27.77 \pm 0.17$ & $5.09 \pm 0.17$ & $5.05 \pm 0.13$ & $1.70 \pm 0.08$ & $3.35 \pm 0.06$ & $66.40 \pm 0.71$ & $0.12 \pm 0.00$ & $0.80 \pm 0.06$ \\
\hline 0.02 & $18.70 \pm 0.54$ & $14.15 \pm 0.60$ & $3.70 \pm 0.09$ & $1.41 \pm 0.05$ & $2.29 \pm 0.04$ & $61.92 \pm 0.47$ & $0.12 \pm 0.00$ & $1.10 \pm 0.04$ \\
\hline 0.04 & $11.17 \pm 0.52$ & $21.69 \pm 0.44$ & $2.71 \pm 0.05$ & $1.34 \pm 0.06$ & $1.38 \pm 0.01$ & $50.72 \pm 1.20$ & $0.12 \pm 0.01$ & $1.32 \pm 0.01$ \\
\hline 0.06 & $6.30 \pm 0.51$ & $26.56 \pm 0.51$ & $1.60 \pm 0.04$ & $0.97 \pm 0.04$ & $0.63 \pm 0.01$ & $39.30 \pm 0.66$ & $0.10 \pm 0.01$ & $0.91 \pm 0.01$ \\
\hline 0.08 & $4.66 \pm 0.46$ & $28.20 \pm 0.52$ & $1.24 \pm 0.08$ & $0.92 \pm 0.05$ & $0.33 \pm 0.04$ & $26.26 \pm 1.21$ & $0.07 \pm 0.01$ & $0.63 \pm 0.04$ \\
\hline 0.11 & $3.39 \pm 0.61$ & $29.47 \pm 0.61$ & $0.77 \pm 0.03$ & $0.66 \pm 0.03$ & $0.12 \pm 0.01$ & $14.87 \pm 0.41$ & $0.03 \pm 0.01$ & $0.32 \pm 0.01$ \\
\hline
\end{tabular}

Table 2). In fact, the presence of more yeast extract and peptone in the nitrogen-limited acetate medium might promote cell proliferation rather than lipid biosynthesis. As a result, the consumed $\mathrm{C} / \mathrm{N}$ ratio remained low and disfavored higher lipid contents [34]. The lipid productivity increased when the dilution rate increased from 0.01 to $0.04 \mathrm{~h}^{-1}$, and then dropped when the dilution rate increased beyond $0.06 \mathrm{~h}^{-1}$ (Table 3). The highest lipid productivity was $1.32 \mathrm{~g} / \mathrm{L} / \mathrm{d}$ at the dilution rate of $0.04 \mathrm{~h}^{-1}$, which was higher than those under nitrogenrich conditions.

As shown in Fig. 4, the specific acetate consumption rate increased along with the dilution rate. The maximal specific acetate consumption rate reached $0.57 \mathrm{~g} / \mathrm{g}$ non-lipid cell mass/h at a dilution rate of $0.11 \mathrm{~h}^{-1}$. The specific lipid formation rate increased when the dilution rate increased from 0.01 to $0.04 \mathrm{~h}^{-1}$, albeit the lipid content decreased from 66.4 to $50.7 \%$. However, the specific lipid formation rate dropped when the dilution rate went beyond $0.06 \mathrm{~h}^{-1}$ (Fig. 5). Similar trends between the specific lipid formation rate and the dilution rate have been found for other oleaginous yeasts growing on glucose

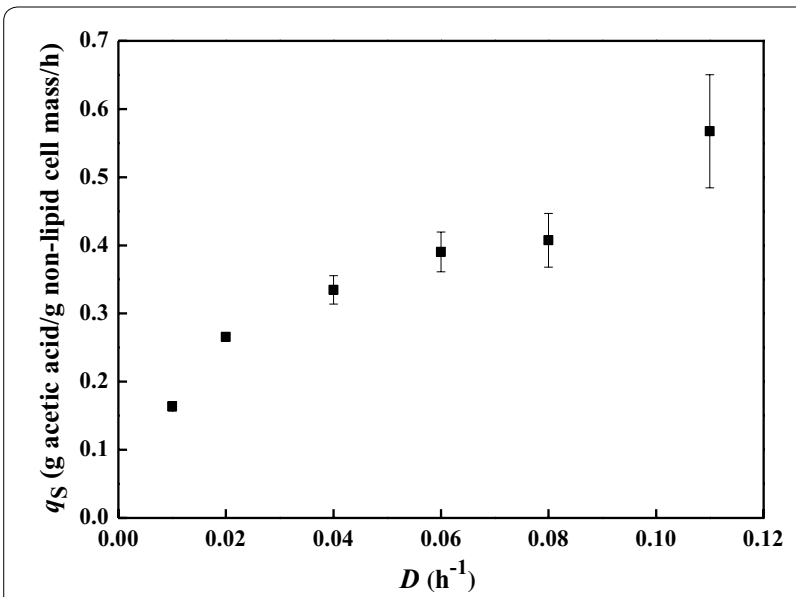

Fig. 4 Steady-state specific acetic acid consumption rates of $C$. curvatus at different dilution rates under nitrogen-limited conditions. Error bars mean \pm standard deviation of four samples
$[24,35]$. The maximal specific lipid formation rate of $0.041 \mathrm{~g} / \mathrm{g}$ non-lipid cell mass/h was observed at the dilution rate of $0.04 \mathrm{~h}^{-1}$, which was obviously lower than that under nitrogen-rich conditions. However, the result was 2.5-fold higher than that obtained by Candida curvata on glucose under nitrogen-limited conditions at the same dilution rate [36].

\section{Lipid production on corn stover hydrolysates containing acetate}

To further demonstrate the capacity of lipid production by $C$. curvatus on acetate, we did enzymatic hydrolysis of alkaline-pretreated corn stover in an acetate buffer and generated the hydrolysates containing $19.2 \mathrm{~g} / \mathrm{L}$ glucose, $9.2 \mathrm{~g} / \mathrm{L}$ xylose and $15.9 \mathrm{~g} / \mathrm{L}$ acetate. The hydrolysates were used to culture C. curvatus at $\mathrm{pH} 7.0$ for $60 \mathrm{~h}$, and the results are shown in Fig. 6. It was found that acetate was assimilated simultaneously with glucose, and that glucose, xylose and acetate were all consumed after $60 \mathrm{~h}$ (Fig. 6a). The residual glucose and acetate were both below $1.0 \mathrm{~g} / \mathrm{L}$ within $36 \mathrm{~h}$. Cell mass, lipid titre and lipid content increased over time (Fig. 6b). Cell mass, lipid titre, lipid content, lipid yield and lipid productivity were

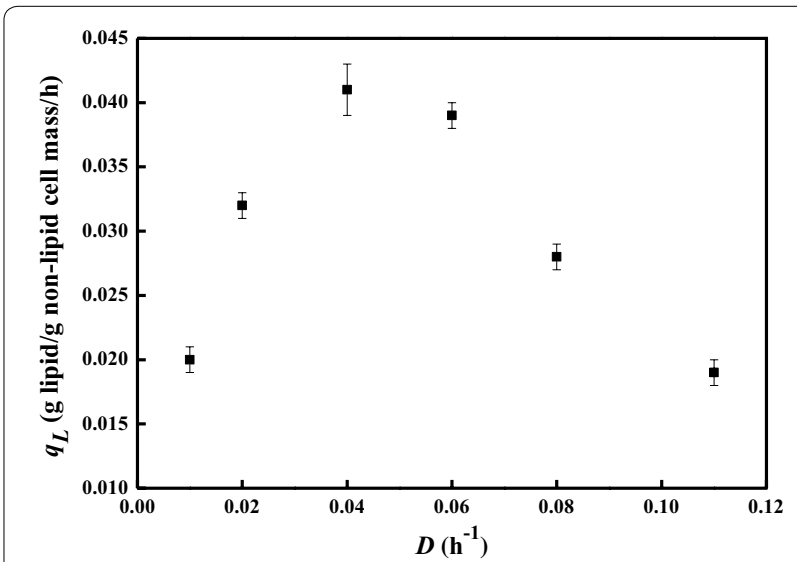

Fig. 5 Steady-state specific lipid formation rates of C. curvatus at different dilution rates under nitrogen-limited conditions. Error bars mean \pm standard deviation of four samples 

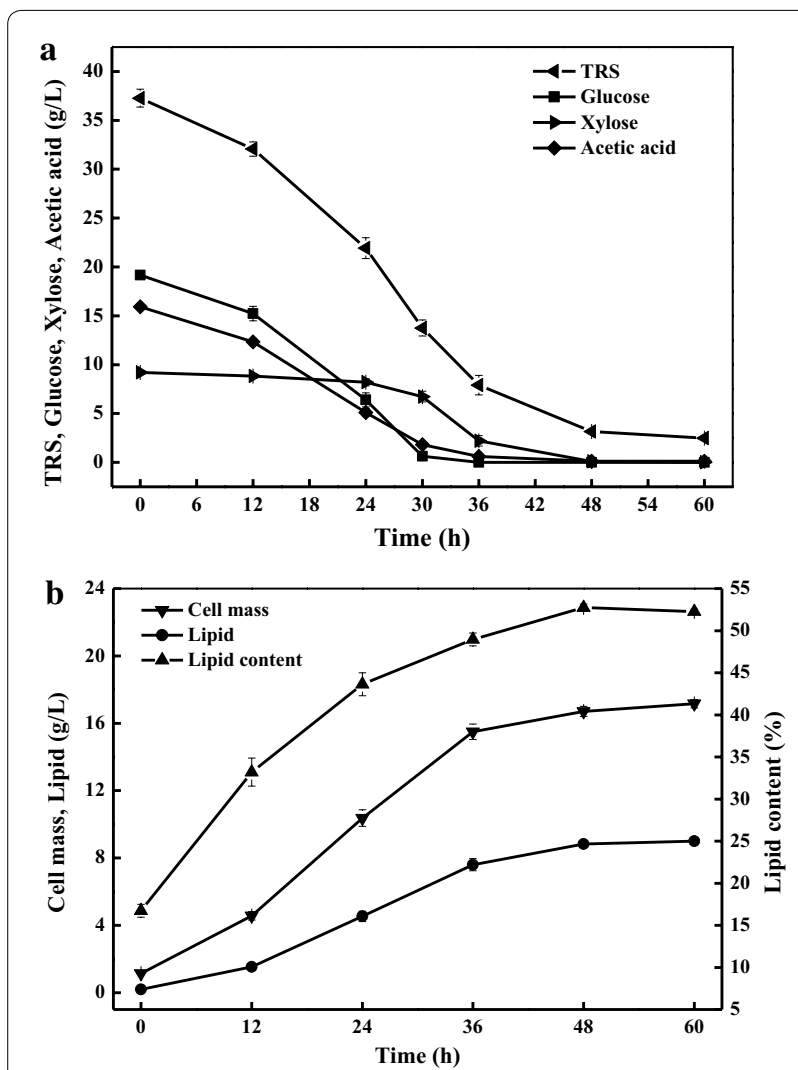

Fig. 6 Results of lipid production by C. curvatus on corn stover hydrolysates containing acetate. a Profiles of substrates consumption. b Profiles of cell growth and lipid accumulation. Error bars mean \pm standard deviation of three samples

17.2, $9.0 \mathrm{~g} / \mathrm{L}, 52.3 \%, 0.18 \mathrm{~g} / \mathrm{g}$ substrate and $3.6 \mathrm{~g} / \mathrm{L} / \mathrm{d}$, respectively. An overall lipid titre of $9.0 \mathrm{~g} / \mathrm{L}$ is an indication that acetate indeed contributed substantially for lipid synthesis, as lipid yield would reach an unrealistic value of $0.32 \mathrm{~g} / \mathrm{g}$ sugar. Furthermore, the lipid productivity was also several folds higher than those using acetate alone as substrate, suggesting a useful strategy to improve the rate of lipid production on acetate by addition of sugar [37]. Overall, our results suggest that acetate presented in biomass hydrolysates is effective carbon source for microbial lipid production.

\section{Conclusions}

Acetate can be converted into microbial lipids by several oleaginous yeasts. Continuous conversion of acetate into lipids was promising under both nitrogen-rich and nitrogen-limited conditions by $C$. curvatus. The maximal specific lipid formation rate and lipid yield were higher under nitrogen-rich than nitrogen-limited conditions, which provided new opportunity for lipid overproduction from acetate-contained resources rich in nitrogen sources. Our results also suggest that biomass hydrolysates containing acetate are suitable for microbial lipid production. Further work should focus on elucidating the mechanisms of lipogenesis on acetate by oleaginous yeasts and developing more robust processes.

\section{Methods}

\section{Strains and media}

C. curvatus ATCC 20509 and R. toruloides ATCC 10788 were purchased from the American Type Culture Collection. T. fermentans CICC 1368 was purchased from the China Center of Industrial Culture Collection. Lipomyces starkeyi AS 2.1560, Y. lipolytica AS 2.1398, T cutaneum AS 2.571, Rhodotorula glutinis AS 2.107, Rhodotorula mucilaginosa AS 2.1515 and Rhodotorula minuta AS 2.277 were obtained from the China General Microbiological Culture Collection Center (CGMCC). R. toruloides Y4 was a derivative of $R$. toruloides AS 2.1389 obtained from CGMCC. The oleaginous yeasts were stored at $4{ }^{\circ} \mathrm{C}$ and propagated every 2 weeks on yeast peptone dextrose (YPD) agar slants (yeast extract $10 \mathrm{~g} / \mathrm{L}$, peptone $10 \mathrm{~g} / \mathrm{L}$, glucose $20 \mathrm{~g} / \mathrm{L}$, agar $15 \mathrm{~g} / \mathrm{L}, \mathrm{pH}$ 6.0). Yeasts inocula were prepared from YPD liquid medium (yeast extract $10 \mathrm{~g} / \mathrm{L}$, peptone $10 \mathrm{~g} / \mathrm{L}$, glucose $20 \mathrm{~g} / \mathrm{L}, \mathrm{pH}$ 6.0).

Acetate assimilation medium (g/L): Acetic acid 30, $\mathrm{NH}_{4} \mathrm{Cl} 1.07, \mathrm{H}_{3} \mathrm{PO}_{4} 0.58, \mathrm{KCl} 0.15, \mathrm{Na}_{2} \mathrm{SO}_{4} 1.2, \mathrm{CaCl}_{2}$ $0.22, \mathrm{MgCl}_{2} \cdot 6 \mathrm{H}_{2} \mathrm{O} 0.41, \mathrm{FeCl}_{2} \cdot 4 \mathrm{H}_{2} \mathrm{O} 0.0004$ and vitamin stock solution $10 \mathrm{~mL} / \mathrm{L}$. Initial $\mathrm{pH}$ was brought to 7.0 by adding an appropriate amount of solid $\mathrm{NaOH}$. The carbon-to-nitrogen $(\mathrm{C} / \mathrm{N})$ molar ratio of the medium was 50 .

Nitrogen-rich acetate medium $(\mathrm{g} / \mathrm{L})$ : Acetic acid 5, $\mathrm{NH}_{4} \mathrm{Cl} 5$, yeast extract 0.1 , peptone $0.1, \mathrm{H}_{3} \mathrm{PO}_{4} 0.58$, $\mathrm{KCl} 0.15, \mathrm{Na}_{2} \mathrm{SO}_{4} 1.2, \mathrm{CaCl}_{2} 0.22, \mathrm{MgCl}_{2} \cdot 6 \mathrm{H}_{2} \mathrm{O} 0.41$, $\mathrm{FeCl}_{2} \cdot 4 \mathrm{H}_{2} \mathrm{O} 0.0004$ and vitamin stock solution $10 \mathrm{~mL} / \mathrm{L}$. Initial $\mathrm{pH}$ was brought to 7.0 by adding an appropriate amount of solid $\mathrm{NaOH}$. This medium had a $\mathrm{C} / \mathrm{N}$ ratio of 1.76 .

Nitrogen-limited acetate medium (g/L): Acetic acid 30, $\mathrm{NH}_{4} \mathrm{Cl} 1.07$, yeast extract 0.5 , peptone $0.5, \mathrm{H}_{3} \mathrm{PO}_{4} 0.58$, $\mathrm{KCl} 0.15, \mathrm{Na}_{2} \mathrm{SO}_{4} 1.2, \mathrm{CaCl}_{2} 0.22, \mathrm{MgCl}_{2} \cdot 6 \mathrm{H}_{2} \mathrm{O} 0.41$, $\mathrm{FeCl}_{2} \cdot 4 \mathrm{H}_{2} \mathrm{O} 0.0004$ and vitamin stock solution $10 \mathrm{~mL} / \mathrm{L}$. Initial $\mathrm{pH}$ was brought to 7.0 by adding an appropriate amount of solid $\mathrm{NaOH}$. The medium had a $\mathrm{C} / \mathrm{N}$ ratio of 35.5 .

Vitamin stock solution ( $\mathrm{mg} / \mathrm{L})$ : thiamine hydrochloride 50 , riboflavin 50 , nicotinic acid 50 , pantothenic acid 50 , pyridoxine hydrochloride 10 , biotin 20 , folic acid 20 , 4-aminobenzoic acid 50, cyanocobalamin 50, thioctic acid 50. It was filtered through $0.22 \mu \mathrm{m}$ microporous membrane before added to the sterilized media.

Yeast extract (containing $3 \%$ [wt/wt] ammonium-N and $9.0 \%$ [wt/wt] total nitrogen) and peptone (animaltissue based containing $3 \%$ [wt/wt] ammonium-N 
and $14.5 \%$ [wt/wt] total nitrogen) were obtained from Aoboxing Biotech. Co. Ltd. (Beijing, China). Antifoam 204, a mixture of organic polyether dispersions, was purchased from Sigma. Other reagents used were analytical grade and purchased from local company.

All the media were autoclaved at $121{ }^{\circ} \mathrm{C}$ for $18 \mathrm{~min}$ before use. Antifoam $2040.1 \%$ (w/v) was added for cultures in bioreactor.

\section{Batch culture}

All pre-cultures were made in YPD medium at $30{ }^{\circ} \mathrm{C}$, $200 \mathrm{rpm}$ for $24 \mathrm{~h}$ unless otherwise specified. Cultures were initiated upon $45 \mathrm{~mL}$ of the acetate assimilation medium inoculated with $5 \mathrm{~mL}$ of pre-cultures in $250-\mathrm{mL}$ unbaffled conical flasks. The cultures were held at $30^{\circ} \mathrm{C}$, $200 \mathrm{rpm}$ for $72 \mathrm{~h}$. Experiments were done in duplicates.

To $1.8 \mathrm{~L}$ of acetate assimilation medium was inoculated with $200 \mathrm{~mL}$ of pre-cultures, and the culture was performed at $30{ }^{\circ} \mathrm{C}, \mathrm{pH} 7.0$ in a 3-L stirred-tank bioreactor (Baoxing Biotechnology Inc., Shanghai, China). Agitation and aeration rate were set at $500 \mathrm{rpm}$ and $0.8 \mathrm{vvm}$, respectively. The culture $\mathrm{pH}$ was maintained at 7.0 by automatic addition of $2 \mathrm{M} \mathrm{H}_{2} \mathrm{SO}_{4}$.

\section{Chemostat continuous culture}

Pre-cultures $10 \%(\mathrm{v} / \mathrm{v})$ were inoculated to $1.8 \mathrm{~L}$ of acetate assimilation medium. The culture was initiated at $30{ }^{\circ} \mathrm{C}, \mathrm{pH} 7.0$, with agitation and aeration rate of $500 \mathrm{rpm}$ and $0.8 \mathrm{vvm}$, respectively. The culture was changed to a continuous mode at $24 \mathrm{~h}$ with a specific dilution rate. Nitrogen-rich and nitrogen-limited chemostat continuous cultures were performed with a working volume of $1.85 \mathrm{~L}$ at $30^{\circ} \mathrm{C}, \mathrm{pH}$ 7.0. Agitation and aeration rate were maintained at $500 \mathrm{rpm}$ and $0.8 \mathrm{vvm}$, respectively. Feeding medium and deformer were pumped into the bioreactor by a peristaltic pump (BT100-2J, Baoding Longer Precision Pump Co., Ltd). The chemostat were maintained at least four complete volume changes before sampling. It was assumed that steady states reached when cell and substrate concentrations changed less than $5 \%$ within $12 \mathrm{~h}$, while dissolved oxygen $\left(\mathrm{dO}_{2}\right)$ output was used as the indicator for any perturbation [38]. Four samples for each steady state were collected at 4-h interval for analysis through the outlet port. Dilution rates were set ranging from 0.04 to $0.14 \mathrm{~h}^{-1}$ for nitrogen-rich culture and 0.01 to $0.11 \mathrm{~h}^{-1}$ for nitrogen-limited culture. The culture was shifted from the steady state at a higher dilution rate to the steady state at a lower dilution rate.

\section{Lipid production on corn stover hydrolysates containing acetate}

Corn stover was alkaline-pretreated according to a published procedure and hydrolyzed using enzymes as described [29]. Briefly, the pretreated corn stover was loaded at $5 \%(\mathrm{w} / \mathrm{v})$ solid loading in $0.3 \mathrm{M}$ acetate buffer $(\mathrm{pH} 4.8)$ and hydrolyzed at $50^{\circ} \mathrm{C}$ for $48 \mathrm{~h}$ in the presence of $20 \mathrm{FPU}$ cellulase, $40 \mathrm{CBU} \beta$-glucosidase and $5 \mathrm{mg}$ xylanase per gram regenerated corn stover. The hydrolysates were boiled for $5 \mathrm{~min}$, centrifuged and supplemented with $2 \mathrm{~g} / \mathrm{L}\left(\mathrm{NH}_{4}\right)_{2} \mathrm{SO}_{4}$. The $\mathrm{pH}$ of the hydrolysates was adjusted to 7.0 before sterilization.

Cultures were initiated upon $45 \mathrm{~mL}$ of the hydrolysates inoculated with $5 \mathrm{~mL}$ of pre-cultures in $250-\mathrm{mL}$ unbaffled conical flasks. The cultures were held at $30{ }^{\circ} \mathrm{C}, 200 \mathrm{rpm}$ for $60 \mathrm{~h}$. Cultivation $\mathrm{pH}$ was adjusted to 7.0 in 12-h time intervals. Experiments were done in triplicates.

\section{Analytical method}

Glucose was determined using an SBA-40E glucose analyzer (Shandong Academy of Sciences, Jinan, China). Total reducing sugars (TRS) were quantified according to the 2, 4-dinitrosalicylate method with glucose as standard [39]. Xylose and acetate were measured by K-XYLOSE and K-ACETAF assay kit, respectively, from Megazyme [40].

Cell mass was determined gravimetrically after drying cells from certain volume of the culture broth at $105{ }^{\circ} \mathrm{C}$ overnight. Non-lipid cell mass was calculated after subtraction of lipids extracted from cell mass.

Lipid extraction was performed according to a published procedure [41]. Lipid content was expressed as gram lipid per gram dry cell weight. Lipid yield was calculated as gram lipid per gram carbon source consumed. The fatty acid compositional profiles of lipid samples were determined using a 7890F gas chromatography instrument after transmethylation according to a published procedure [26].

Acetate concentration $\left(C_{S}\right)$ and lipid concentration $\left(C_{\mathrm{L}}\right)$ were constant within bioreactor at steady state. So, the specific substrate uptake rate $\left(q_{\mathrm{S}}, \mathrm{g} / \mathrm{g}\right.$ non-lipid cell mass/h) and the specific lipid formation rate $\left(q_{\mathrm{L}}, \mathrm{g} / \mathrm{g}\right.$ nonlipid cell mass/h) were calculated according to formulas (1) and (2), respectively.

$$
\begin{aligned}
& q_{\mathrm{S}}=\frac{\left(C_{\mathrm{S}_{0}}-C_{\mathrm{S}}\right)}{C_{\text {Non-lipid cell mass }}} \times D \\
& q_{\mathrm{L}}=\frac{\left(C_{\mathrm{L}}-C_{\mathrm{L}_{0}}\right)}{C_{\text {Non-lipid cell mass }}} \times D
\end{aligned}
$$

$C_{S_{0}}$ is the acetate concentration of the solution used to feed the bioreactor, $\mathrm{g} / \mathrm{L} ; C_{\mathrm{L}_{0}}$ is the lipid concentration of the cells used to inoculate the bioreactor and equal to zero, $\mathrm{g} / \mathrm{L}$.

\section{Abbreviations}

C: concentration; $\mathrm{CBU}$ : cellobiase unit; $\mathrm{C} / \mathrm{N}$ : carbon-to-nitrogen; D: dilution rate; DCW: dry cell weight; FPU: filter paper unit; pKa: the negative logarithm 
of dissociation constant; $q_{\mathrm{S}}$ : the specific acetate uptake rate; $q_{\mathrm{L}}$ : the specific lipid formation rate; TRS: total reducing sugars; VFAs: volatile fatty acids; YPD: yeast peptone dextrose.

\section{Authors' contributions}

ZWG designed the study, performed the lipid production experiments, analyzed the results and drafted the manuscript. HWS participated in experiment designing and continuous culture. WTZ participated in lipid production on corn stover hydrolysates and sugar analysis. XBY participated in continuous culture. YDW participated in lipid production experiments and acetate analysis. ZKZ conceived the study, participated in its design and coordination and revised the manuscript. All authors read and approved the final manuscript.

\section{Acknowledgements}

This work was financially supported by the National Natural Science Foundation of China (21325627), the Young Scientists Foundation of Wuhan University of Science and Technology (2015XZ013) and the National Basic Research and Development Program of China (2011CB707405).

\section{Competing interests}

The authors declare that they have no competing interests.

Received: 16 June 2015 Accepted: 28 October 2015

Published online: 25 November 2015

\section{References}

1. Huang C, Chen XF, Xiong L, Chen XD, Ma LL, Chen Y. Single cell oil production from low-cost substrates: the possibility and potential of its industrialization. Biotechnol Adv. 2013;31:129-39.

2. Jin MJ, Slininger PJ, Dien BS, Waghmode S, Moser BR, Orjuela A, Sousa Lda C, Balan V. Microbial lipid-based lignocellulosic biorefinery: feasibility and challenges. Trends Biotechnol. 2015;33:43-54.

3. Papanikolaou S, Aggelis G. Lipids of oleaginous yeasts. Part I: Biochemistry of single cell oil production. Eur J Lipid Sci Technol. 2011;113:1031-51.

4. Ratledge C, Wynn JP. The biochemistry and molecular biology of lipid accumulation in oleaginous microorganisms. Adv Appl Microbiol. 2002;51:1-51.

5. Wu SG, Hu CM, Jin GJ, Zhao X, Zhao ZBK. Phosphate-limitation mediated lipid production by Rhodosporidium toruloides. Bioresour Technol. 2010;101:6124-9.

6. Palmqvist E, Hahn-Hagerdal B. Fermentation of lignocellulosic hydrolysates. II: inhibitors and mechanisms of inhibition. Bioresour Technol. 2000;74:25-33.

7. Chen X, Li ZH, Zhang XX, Hu FX, Ryu DDY, Bao J. Screening of oleaginous yeast strains tolerant to lignocellulose degradation compounds. Appl Biochem Biotechnol. 2009;159:591-604.

8. Younesi H, Najafpour G, Mohamed AR. Ethanol and acetate production from synthesis gas via fermentation processes using anaerobic bacterium Clostridium ljungdahlii. Biochem Eng J. 2005;27:110-9.

9. Henstra AM, Sipma J, Rinzema A, Stams AJM. Microbiology of synthesis gas fermentation for biofuel production. Curr Opin Biotechnol. 2007;18:200-6.

10. Chi ZY, Zheng YB, Ma JW, Chen SL. Oleaginous yeast Cryptococcus curvatus culture with dark fermentation hydrogen production effluent as feedstock for microbial lipid production. Int J Hydrogen Energ. 2011;36:9542-50.

11. Xu X, Ji YK, Hyun UC, Hye RP, Jong MP. Bioconversion of volatile fatty acids from macroalgae fermentation into microbial lipids by oleaginous yeast. Chem Eng J. 2015;264:735-43.

12. Straub M, Demler M, Weuster-Botz D, Durre P. Selective enhancement of autotrophic acetate production with genetically modified Acetobacterium woodii. J Biotechnol. 2014;178:67-72.

13. Zhang GC, French WT, Hernandez R, Alley E, Paraschivescu M. Effects of furfural and acetic acid on growth and lipid production from glucose and xylose by Rhodotorula glutinis. Biomass Bioenerg. 2011;35:734-40.

14. Huang C, Wu H, Liu ZJ, Cai J, Lou WY, Zong MH. Effect of organic acids on the growth and lipid accumulation of oleaginous yeast Trichosporon fermentans. Biotechnol Biofuels. 2012;5:4.
15. Hu CM, Zhao X, Zhao J, Wu SG, Zhao ZBK. Effects of biomass hydrolysis by-products on oleaginous yeast Rhodosporidium toruloides. Bioresour Technol. 2009;100:4843-7.

16. Ruan ZH, Hollinshead W, Isaguirre C, Tang YJ, Liao W, Liu Y. Effects of inhibitory compounds in lignocellulosic hydrolysates on Mortierella isabellina growth and carbon utilization. Bioresour Technol. 2015;183:18-24.

17. Lian JN, Garcia-Perez M, Coates R, Wu HW, Chen SL. Yeast fermentation of carboxylic acids obtained from pyrolytic aqueous phases for lipid production. Bioresour Technol. 2012;118:177-86.

18. Fei Q, Chang HN, Shang L, Choi JD, Kim N, Kang J. The effect of volatile fatty acids as a sole carbon source on lipid accumulation by Cryptococcus albidus for biodiesel production. Bioresour Technol. 2011;102:2695-701.

19. Christophe G, Deo JL, Kumar V, Nouaille R, Fontanille P, Larroche C. Production of oils from acetic acid by the oleaginous yeast Cryptococcus curvatus. Appl Biochem Biotechnol. 2012;167:1270-9.

20. Fontanille P, Kumar V, Christophe G, Nouaille R, Larroche C. Bioconversion of volatile fatty acids into lipids by the oleaginous yeast Yarrowia lipolytica. Bioresour Technol. 2012;114:443-9.

21. Beligon V, Poughon L, Christophe G, Lebert A, Larroche C, Fontanille P. Improvement and modeling of culture parameters to enhance biomass and lipid production by the oleaginous yeast Cryptococcus curvatus grown on acetate. Bioresour Technol. 2015;192:582-91.

22. Hall MJ, Ratledge C. Lipid accumulation in an oleaginous yeast (Candida 107) growing on glucose under various conditions in a one- and twostage continuous culture. Appl Environ Microbiol. 1977;33:577-84.

23. Papanikolaou S, Aggelis G. Lipid production by Yarrowia lipolytica growing on industrial glycerol in a single-stage continuous culture. Bioresour Technol. 2002;82:43-9.

24. Ykema A, Verbree EC, van Verseveld HW, Smit H. Mathematical modelling of lipid production by oleaginous yeasts in continuous cultures. Antonie Van Leeuwenhoek. 1986;52:491-506.

25. Shen HW, Gong ZW, Yang XB, Jin GJ, Bai FW, Zhao ZBK. Kinetics of continuous cultivation of the oleaginous yeast Rhodosporidium toruloides. J Biotechnol. 2013;168:85-9.

26. Li YH, Zhao ZBK, Bai FW. High-density cultivation of oleaginous yeast Rhodosporidium toruloides $Y 4$ in fed-batch culture. Enzyme Microb Technol. 2007:41:312-7.

27. Yu XC, Zheng YB, Dorgan KM, Chen SL. Oil production by oleaginous yeasts using the hydrolysate from pretreatment of wheat straw with dilute sulfuric acid. Bioresour Technol. 2011;102:6134-40.

28. Pedersen TA. Lipid formation in Cryptococcus terricolus 1. Nitrogen nutrition and lipid formation. Acta Chem Scand. 1961;15:651-62.

29. Gong ZW, Shen HW, Yang XB, Wang Q, Xie HB, Zhao ZBK. Lipid production from corn stover by the oleaginous yeast Cryptococcus curvatus. Biotechnol Biofuels. 2014;7:158.

30. Liu B, Zhao ZBK. Biodiesel production by direct methanolysis of oleaginous microbial biomass. J Chem Technol Biotechnol. 2007;82:775-80.

31. Sattur AP, Karanth NG. Production of microbial lipids: 3. Influence of C/N ratio_experimental observations. Biotechnol Bioeng. 1989;34:872-4.

32. Economou CN, Aggelis G, Pavlou S, Vayenas DV. Single cell oil production from rice hulls hydrolysate. Bioresour Technol. 2011;102:9737-42.

33. Zheng YB, Chi ZY, Ahring BK, Chen SL. Oleaginous yeast Cryptococcus curvatus for biofuel production: ammonia's effect. Biomass Bioenerg. 2012;37:114-21.

34. Granger LM, Perlot P, Goma G, Pareilleux A. Efficiency of fatty acid synthesis by oleaginous yeasts: prediction of yield and fatty acid cell content from consumed C/N ratio by a simple method. Biotechnol Bioeng. 1993:42:1151-6.

35. Brown BD, Hsu KH, Hammond EG, Glatz BA. A relationship between growth and lipid accumulation in Candida curvata D. J Ferment Bioeng. 1989;68:344-52.

36. Evans CT, Ratledge C. A comparison of the oleaginous yeast, Candida curvata, grown on different carbon sources in continuous and batch culture. Lipids. 1983;18:623-9.

37. Wei N, Quarterman J, Kim SR, Cate JHD, Jin YS. Enhanced biofuel production through coupled acetic acid and xylose consumption by engineered yeast. Nat Commun. 2013;4:2580.

38. Ganuza E, Izquierdo MS. Lipid accumulation in Schizochytrium G13/2S produced in continuous culture. Appl Microbiol Biotechnol. 2007;76:985-90 
39. Miller GL. Use of dinitrosalicylic acid reagent for determination of reducing sugar. Anal Chem. 1959;31:426-8.

40. Kabel MA, Yeoman CJ, Han Y, Dodd D, Abbas CA, de Bont JA, Morrison M, Cann IK, Mackie RI. Biochemical characterization and relative expression levels of multiple carbohydrate esterases of the xylanolytic rumen bacterium Prevotella ruminicola 23 grown on an ester-enriched substrate. Appl Environ Microbiol. 2011;77:5671-81.
41. Gong ZW, Wang Q, Shen HW, Hu CM, Jin GJ, Zhao ZBK. Co-fermentation of cellobiose and xylose by Lipomyces starkeyi for lipid production. Bioresour Technol. 2012;117:20-4.

\section{Submit your next manuscript to BioMed Central} and take full advantage of:

- Convenient online submission

- Thorough peer review

- No space constraints or color figure charges

- Immediate publication on acceptance

- Inclusion in PubMed, CAS, Scopus and Google Scholar

- Research which is freely available for redistribution

Submit your manuscript at

www.biomedcentral.com/submit

() BioMed Central 